2 Gorevic PD, Kassab HJ, Levo Y, et al. Mixed cryoglobulinaemia: clinical aspects and long-term follow-up of 40 patients. Am $\mathcal{f}$ Med 1980;69:287-308. McVerry BA, Voke J, Mohammed I, Dormandy KM, Holborow Ej. Immune complexes and abnormal liver function in haemophilia. 7 Clin Pathol 1977;30: $1142-6$.

4 Hilgartner MW. Immune complex disease in haemophilia. In: Forbes CD, Lowe GDO, eds. Unresolved problems in haemophilia. Lancaster: MTP Press, 1980

(hiferli JA, Peters DK. Complement, the immune-complex lattice and the patho.

(Accepted 12 April 1985)

Haemophilia Centre and Haemostasis Unit, Academic Department of Haematology, Royal Free Hospital, London

C A LEE, MRCP, MRCPATH, honorary lecturer

P B A KERNOFF, MD, MRCP, consultant haematologist

Royal Postgraduate Medical School, Hammersmith Hospital, London

D K PETERS, FRCP, professor of medicine

Correspondence to: Dr C A Lee, Department of Haematology, Queen Mary's Hospital, London SW15 5PN.

\section{Laser irradiation of inoperable tumours of the colon and rectum}

Laser treatment of upper gastrointestinal bleeding is of proved value, ${ }^{1}$ as is treatment of oesophagogastric tumours. ${ }^{2} \mathrm{We}$ have also used laser irradiation to produce palliation in patients with inoperable primary or recurrent colorectal cancers who have had distressing symptoms.

\section{Patients, methods, and results}

Fifteen patients (mean age 73.3) were referred. Five had a recurrence of tumour after Hartmann's procedure. Eight with inoperable anorectal tumours and two with otherwise untreatable dysplastic polyps were also referred. Most of the patients had distressing, foul smelling, and often bloody rectal discharge. In others intestinal obstruction was imminent. They were initially admitted overnight, but subsequently the procedure was carried out on an outpatient basis. Minimal preparation was required. At first all were given intravenous diazepam, but later many were treated without sedation.

The lesion was visualised using a standard flexible endoscope fitted with a protective filter. Laser light was applied through a sheathed $600 \mu$ quartz fibre passed through the biopsy channel. The laser used was a Molectron 8000 neodymium yttrium aluminium garnet laser, set to deliver 80-100 watts in pulses lasting up to 1.0 second. The total energy applied varied but did not exceed $6000 \mathrm{~J}$ per session. Patients began with weekly treatments and then received subsequent treatments at intervals of two to eight weeks as required. The table outlines their progress. One patient died between referral and treatment ${ }^{5}$ : knowing when referral is necessary may be difficult. All patients with a recurrence after Hartmann's procedure showed appreciable reduction in tumour bulk and considerable or even complete relief of discharge and bleeding.

One patient (case 6) had complete ablation of macroscopic growth with subsequent negative biopsy specimens at six months. Two others (cases 7 and 8 ) had symptomatic benefit with reduction in bleeding or discharge, or both, and two further patients (cases 9 and 10) had impending colonic obstruction relieved by creation of a wider lumen. In case 11 the tumour had invaded the perineum and treatment only increased the extent of ulceration. Another patient (case 12) was unable to comment on problems, and we thought it unjustifiable to continue treatment when the locally invasive tumour was found on routine rectal examination. He will be treated if symptoms demand. In case 13 impending obstruction was due to extrinsic compression rather than the adjacent visible recurrence. The laser could not be applied in the final two patients : excessive haemorrhage from the dysplastic polyp in the patient with myelofibrosis meant that adequate visualisation was only possible once, and in case 15 the villous adenoma could not be reached for technical reasons.

No major side effects were noted, although some patients experienced a transient perineal burning sensation during application of the laser. A temporary increase in bleeding or discharge was occasionally noted for one or two days after treatment, probably because of sloughing of the tumour.

\section{Comment}

Laser treatment in these patients aimed at achieving palliation of symptoms, or preventing colonic obstruction, or both. We had greatest success in reducing discharge and bleeding. The repeated courses of treatment may be required at frequencies varying from weekly to bimonthly but are well tolerated. There is also potential for producing and maintaining luminal patency.

Laser irradiation can be delivered to any site accessible to fibreoptic endoscopy, which distinguishes this technique from current methods of endocavity irradiation or diathermy fulguration. The risk of perforation when the technique is used beyond the rectosigmoid junction must temper overenthusiastic use. At present it should only be used for accessible lesions untreatable by conventional techniques.

We thank Sister E C Smith and the staff of the gastrointestinal unit, and in particular the endoscopy theatre nurses, for their help.

1 Swain CP, Bown SG, Storey DW, Northfield TC, Kirkham JS, Salmon PR.

Controlled trial of argon laser photocoagulation in bleeding peptic ulcers. Controlled trial of argon.

2 Krasner N, Beard J. Laser irradiation of tumours of the oesophagus and gastric cardia. Br Med F i 1984;288:829.

(Accepted 11 April 1985)

Gastrointestinal Unit, Walton Hospital, Liverpool L9 1AE

ANTHONY I MORRIS, MD, FRCP, consultant physician and senior lecturer in medicine

NEVILLE KRASNER, MD, FRCP, consultant physician

Correspondence to: Dr Anthony Morris, $5 Z$ Link Unit, Royal Liverpool Hospital, Liverpool L7.

Details of patients treated by laser

\begin{tabular}{|c|c|c|c|c|c|c|c|c|c|}
\hline $\begin{array}{l}\text { Case } \\
\text { No }\end{array}$ & Age & Sex & Tumour site & Symptoms & Previous treatment & Concurrent disease & $\begin{array}{l}\text { No of laser } \\
\text { courses }\end{array}$ & Symptomatic result & Progress \\
\hline 1 & 78 & $\mathrm{~F}$ & Hartmann's stump & Discharge, blood & & & 11 & Absent or very & * \\
\hline 2 & 66 & $\mathbf{F}$ & Hartmann's stump & Discharge, blood & $\begin{array}{c}\text { Chemotherapy }+ \\
\text { radiotherapy }\end{array}$ & & 4 & Absent or very & Died of metastases \\
\hline 3 & 78 & $\mathbf{M}$ & Hartmann's stump & Discharge, blood & & & 6 & Absent or very & $*$ \\
\hline 4 & 65 & $\mathbf{M}$ & Hartmann's stump & Discharge & Diathermy & & 4 & Reduced & • \\
\hline 5 & 72 & $\mathbf{M}$ & Hartmann's stump & Discharge, blood & & & 0 & Died before treatment & \\
\hline 6 & 71 & $\mathbf{M}$ & Malignant polyp & Bleeding & & $\begin{array}{l}\text { Decompensated } \\
\text { cirrhosis }\end{array}$ & 2 & Complete ablation & Well 6 months later \\
\hline 7 & 80 & $\mathbf{M}$ & Rectum & Bleeding & Loop colostomy & Chronic bronchitis & 2 & Reduced & Refused therapy; \\
\hline 8 & 63 & $\mathbf{M}$ & Rectum & Bleeding & Resection + & & 4 & Reduced & * \\
\hline 9 & 51 & $\mathbf{M}$ & Rectum & Impending obstruction & & Multiple metastases & 3 & Enhanced luminal & • \\
\hline 10 & 73 & $\mathbf{M}$ & Rectum & Impending obstruction & & Mental deficiency & 4 & Enhanced luminal & $*$ \\
\hline 11 & 77 & $\mathbf{F}$ & Anus & Perineal ulceration & $\begin{array}{c}\text { Colostomy }+ \\
\text { radiotherapy }\end{array}$ & & 2 & $\begin{array}{l}\text { Inappropriate } \\
\text { treatment }\end{array}$ & Died 2 months later \\
\hline 12 & 75 & $\mathbf{M}$ & Rectum & & & $\begin{array}{l}\text { Dementia, chronic } \\
\text { bronchitis }\end{array}$ & 1 & $\begin{array}{c}\text { Inappropriate } \\
\text { treatment }\end{array}$ & * \\
\hline 13 & 64 & $\mathbf{F}$ & $\begin{array}{l}\text { Recurrence at } \\
\text { anastomosis }\end{array}$ & $\begin{array}{l}\text { Impending } \\
\text { obstruction } \\
\text { (extrinsic) }\end{array}$ & Resection & Multiple metastases & 0 & Inappropriate referral & \\
\hline 14 & 72 & $\mathbf{M}$ & $\begin{array}{l}\text { Dysplastic polyp } \\
\text { (transverse colon) }\end{array}$ & Severe bleeding & Attempted diathermy & Myelofibrosis & $\mathbf{I}$ & Inadequate view & Died 2 weeks later \\
\hline 15 & 74 & $\mathbf{M}$ & $\begin{array}{l}\text { Dysplastic villous } \\
\text { adenoma }\end{array}$ & Discharge & Diathermy & $\begin{array}{l}\text { Severe chronic } \\
\text { bronchitis }\end{array}$ & $\mathbf{0}$ & Unable to visualise & \\
\hline
\end{tabular}

- Under review or treatment, or both. 